Mediscope

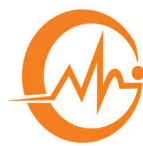

The Journal of GMC

CASE REPORT

\title{
Tuberculous cystitis
}

\author{
MS Mallick
}

\begin{abstract}
Pulmonary tuberculosis is very common but genitourinary tuberculosis, specifically tuberculous cystitis is very rare. A 40 year old male patient came to a teaching hospital on 26 June 2016 with the complaints of fever, painful micturition, haematuria, lower abdominal pain and gradual loss of weight. The case was diagnosed as tuberculous cystitis and treated accordingly and successfully. In this report, the case condition, procedure of diagnosis and treatment are reported in details.
\end{abstract}

Key words: Genitourinary tuberculosis, tuberculous cystitis, treatment.

\section{Introduction}

Tuberculosis (TB) is a current public health problem, remaining the most common worldwide cause of mortality from infectious disease, with an estimated global incidence of 8 to 10 million/year. ${ }^{1-5}$ It is a well known infectious disease of poor socio-economic overcrowding countries like Bangladesh where 3 lacs new patients are diagnosed with TB and 70 thousands of tubercular patients die every year.6,7 Most extrapulmonary forms of TB are seen in organs without optimum conditions for bacterial growth, generally with an insidious onset and a chronic evolution. Recent studies indicate that genitourinary TB is the third most common form of extra-pulmonary disease after peripheral lymphadenopathy. ${ }^{1,3,8}$ The occurrence of extra-pulmonary TB is not common in human immunodeficiency virus negative patients. ${ }^{1,9,10}$

Cystitis is an inflammation of the urinary bladder from any cause. It is a relatively common condition affecting both sexes and all ages. It has no racial predisposition, but females, especially those younger than 50 years, are affected more often than males. In fact, almost every woman may have cystitis at least once in her lifetime. The incidence of cystitis is high in women because of the short length of the urethra and because of the proximity of the urethra to the anus. This anatomy makes the female urinary bladder relatively easily accessible to intestinal pathogens. ${ }^{11-15}$

Cystitis may be symptomatic or asymptomatic. Patients with bladder cystitis may present with symptoms of urgency, frequency, dysuria, haematuria, cloudy and offensivesmelling urine, or suprapubic discomfort. These symptoms may occur singly or in combination. The symptom of urgency results from the stimulation of the afferent arc of the micturition reflex; the offensive smell results from the bacterial conversion of urea to ammonia.

TB can be a causal agent of cystitis and termed as tuberculous cystitis, and among extra pulmonary tuberculosis, genitourinary TB is not uncommon in our country. Recently a case of tuberculous cystitis was clinically

MS Mallick, MBBS, DTCD, Assistant Professor, Department of Medicine, Gazi Medical College Hospital, Khulna.

Email: dr.msmallick53@gmail.com 
and objectively diagnosed, and successfully treated with antitubercular drug regimen in a teaching hospital and was followed up for a period of 6 months. In this report, the case condition, procedure of diagnosis and treatment are reported in details.

\section{Case report}

A 40 years old male patient having a history of close contact with a pulmonary TB patient of his own family living in a overcrowded house in a village came to out-patient department of Prime Medical College Hospital, Rangpur on 26 June 2016 with the complaints of fever, painful micturition, haematuria, lower abdominal pain and gradual loss of weight for 4 weeks. According to the statement of the patient, he was treated locally with two courses of antibiotics but no improvement observed for which he came for proper treatment.

On examination, anaemia, tachycardia, frank haematuria, tenderness of lower abdomen were marked. His weight was $40 \mathrm{~kg}$ and blood pressure 100/60 mmHg. No lymphadenopathy was noted. On auscultation, no abnormality was found in the chest. Regarding blood examination, total leukocyte count was 11500 per $\mathrm{cmm}$, differential leukocyte count showed $82 \%$ of neutrophil and erythrocyte sedimentation rate $100 \mathrm{~mm}$. Urine examination revealed haematuria with pyuria which is suggestive of cystitis. ${ }^{16,17}$ Tuberculin test was positive with a indurations' size of $18 \mathrm{~mm}$. Ultrasonogram of whole abdomen revealed irregular thickening with fibrosis of urinary bladder wall (Fig. 1). X-ray of kidney, ureter, and bladder revealed no evidence of renal calculus. In chest X-ray, no specified opacity or calcified shadow seen. Cystoscopic examination of urinary bladder revealed chronic granulomatous lesion on urinary bladder wall (Fig. 2). The ultrasonographic and cystoscopic findings are suggestive of tuberculous cystitis. ${ }^{18}$

Considering the above clinical features and available investigation reports, the diagnosis was tuberculous cystitis. On the basis of diagnosis, antitubercular drugs were started with appropriate doses and combinations as therapeutic trial and the patient was kept under observation. Within 2 weeks of therapy, patient's main symptoms were relieved. Haematuria, dysuria, fever and lower abdominal pain were relieved and appetite improved. Then the patient was further advised to continue the same treatment. On subsequent visits, general condition of the patient improved day by day. After completion of 6-month therapy with antitubercular drugs he recovered with weight gain.

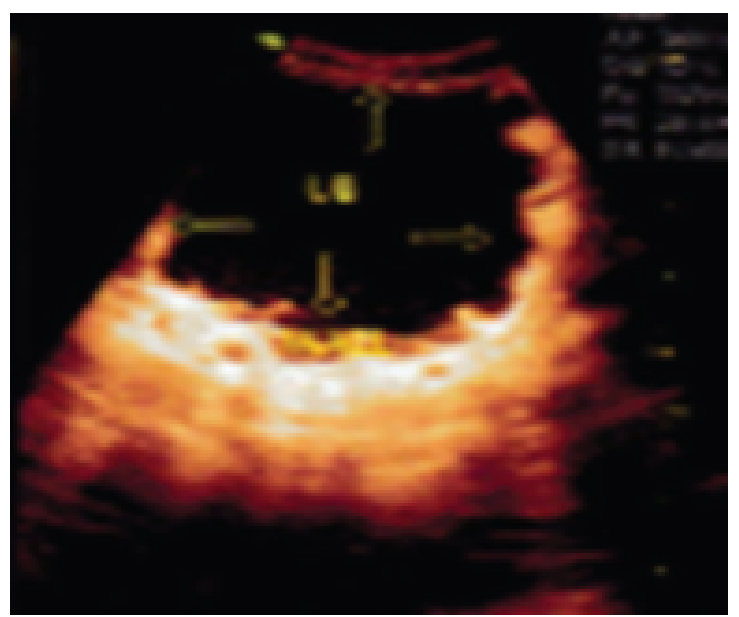

Fig. 1. Ultrasonogram showing irregular thickening with fibrosis of urinary bladder wall.
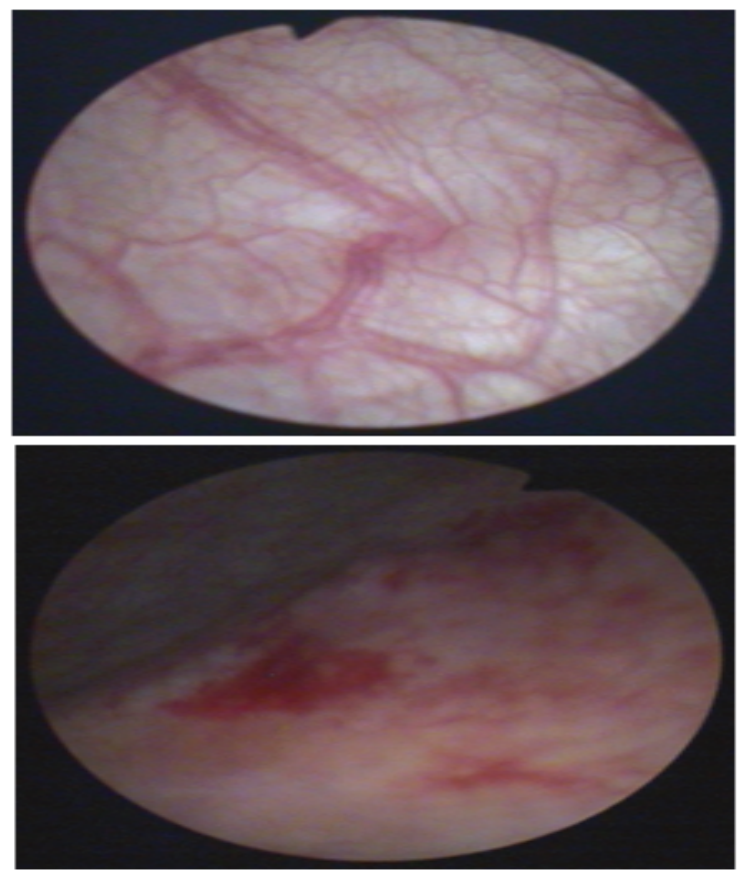

Fig. 2. Cystoscopic examination showing hyperemia and granulomatous lesions on urinary bladder wall. 


\begin{abstract}
Discussion
Sometime the case of tuberculous cystitis is diagnosed as renal or urinary bladder calculus, carcinoma of bladder or a case of urinary tract infection. Among $50-70 \%$ cases, middle aged people with haematuria, dysuria, lower abdominal pain, anorexia, and weight loss are usually diagnosed as case of carcinoma of urinary bladder. Sometimes, haematuria may be present as a symptom of leukemia or aplastic anaemia. But in this case, clinical features and available investigation reports suggested tuberculous cystitis which was treated successfully with antitubercular drugs.
\end{abstract}

TB of renal system is always secondary. It is a result from a primary focus any where in the body or from a haematogenous spread from miliary TB although primary focus is not usually determined. Pyuria is an important feature of genitourinary TB though no acid-fast bacilli is found in ordinary urine examination. ${ }^{19}$ Neutrophilic leucocytosis is an important point of TB of renal system.

According to the guide line of therapeutic option, therapeutic trial can be given for clinically diagnosed extra-pulmonary TB which may give a beneficial effect. ${ }^{20}$ Clinical diagnosis, therapeutic treatment with antitubercular drug regimen and follow-up with a successful result of a rare case of tuberculous cystitis might be useful in medical practice.

\section{References}

1. Eastwood JB, Corbishley CM, Grange JM. Tuberculosis and the kidney. J Am Soc Nephrol 2001;12:1307-14.

2. Gibson MS, Puckett ML, Shelly ME. Renal tuberculosis. Radiographics 2004;24:251-6.

3. Golden MP, Vikram HR. Extrapulmonary tuberculosis: an overview. Am Fam Physician 2005;72:1761-8.

4. Muttarak M, Chiang Mai WN, Lojanapiwat B. Tuberculosis of the genitourinary tract: imaging features with pathological correlation. Singapore Med J 2005;46:568-75.
5. World Health Organization. Global tuberculosis control: WHO report 1998. Geneva, WHO; 1998.

6. Directorate General of Health services \& Ministry of Health and Family Welfare, Bangladesh. Health Bulletin, 2007.

7. Shaheen MNHB. Secrets- A Manual of Clinical Surgery. 2nd edn. Penguin Printers: Cittagong, 2015.

8. Wise GJ, Marella VK. Genitourinary manifestations of tuberculosis. Urol Clin North Am 2003;30:111-21.

9. Daher EF, Silva Júnior GB, Damasceno $\mathrm{RT}$, et al. End-stage renal disease due to delayed diagnosis of renal tuberculosis: a fatal case report. Braz J Infect Dis 2007;11:169-71.

10. Oliveira JL, Silva Junior GB, Daher EF. Tuberculosis-associated chronic kidney disease. Am J Trop Med Hyg 2011;84:843-4.

11.Klutke CG, Klutke JJ. Interstitial cystitis/ painful bladder syndrome for the primary care physician. Can J Urol 2008;1(Suppl):44-52.

12.Seth A, Teichman JM. What's new in the diagnosis and management of painful bladder syndrome/interstitial cystitis? Curr Urol Rep 2008;9(5):349-57.

13.Bharucha AE, Trabuco E. Functional and chronic anorectal and pelvic pain disorders. Gastroenterol Clin North Am 2008;37(3):685-96.

14. Hanno P, Nordling J, van Ophoven A. What is new in bladder pain syndrome/ interstitial cystitis? Curr Opin Urol 2008;18(4):353-8.

15.Klumpp DJ, Rudick CN. Summation model of pelvic pain in interstitial cystitis. Nat Clin Pract Urol 2008;5(9):494-500.

16.CME Pintoo, Ahmed K, Yusuf AMM. An Aid to Short Practice of Surgery. 7th edn. Aid Publication: Dhaka, 2008.

17.Cuschieri A, Giles GR, Moossa AR. Essential surgical practice. Oxford, London, Boston: Butterfield-Heinemann, 1995.

18.Kumar, Abbas, Aster. Robbins and Cotran Pathologic Basis of Diseases. 9th edn, 2017. 
19.Williams NS, Bulstrode CJK, O'Connell PR, (eds). Bailey \& Love's Short Practice of Surgery. 26th edn. CRC Press, 2013.

20.Directorate General of Health services \&
Ministry of Health and Family Welfare, Bangladesh National Guidelines \& Operational Manual of Tuberculosis Control. 5th edn, 2013.

Suggestion for citation of the above:

Mallick MS. Tuberculous cystitis. Mediscope 2017;4(2):35-8. 